\title{
ENFERMAGEM - MURAL - 19/09/05
}

\section{4}

Adesão ao tratamento de pacientes com doença arterial coronária sintomática com tratamento cirúrgico, angioplastia e clínico: MASS II Study: seguimento $\mathbf{4 8}$ meses.

Teryo Nakano, Priscyla Girardi, Celia Regina S R Nogueira, Myrthes Emy Takiuti, Jurema Paloma, Neuza Lopes, Whady Armindo Hueb.

INCOR São Paulo SP BRASIL.

INTRODUÇÃO: A adesão ao tratamento é uma das principais dificuldades na avaliação do sucesso do tratamento em patologias crônicas, tais como coronariopatia. OBJETIVO: Objetivamos avaliar e comparar a adesão ao tratamento dos três grupos de tratamento do MASS II, acompanhados por 48 meses.

Método: A adesão ao tratamento dos pacientes foi avaliado por meio de entrevistas no pré-tratamento, $6,12,24,36$ e 48 meses de seguimento. Foi considerado como adesão: o uso regular das medicações prescritas, capacidade de descrever corretamente as medicações utilizadas e assiduidade às consultas médicas. Ao total de 611 pacientes, 203 foram submetidos à Revascularização Miocárdica (RM), 205 submetidos à Angioplastia ( $\mathrm{PCl})$ e 203 pacientes ao tratamento clínico. RESULTADOS: Quanto à capacidade de descrever corretamente as medicações utilizadas, estratificou-se a análise quanto ao sexo, nos 12, 24, 36 e 48 meses de seguimento, o sexo masculino passou a saber mais que o sexo feminino. Em relação a idade, observou-se que os pacientes $>65$ anos sabem menos os nomes das medicações em relação aos pacientes mais novos no pré-cirúrgico. Analisando o nível de escolaridade em relação à aderência ao tratamento, fo verificado que em relação ao uso de medicamento o grupo com < escolaridade aderem mais às medicações prescritas que no grupo com $>$ escolaridade ( $p=$ $0,027)$ No aspecto assiduidade, não foi verificado diferença entre os grupos no inicio do tratamento e após 6 meses de seguimento o grupo de < escolaridade apresenta um índice de assiduidade de $84.8 \%$ contra $93.6 \%$ no grupo de $>$ escolaridade $(p=0,004)$.

CONCLUSÃO: Concluímos que os pacientes mais jovens e do sexo masculino demonstravam maior conhecimento das medicações em uso e existia uma menor adesão no grupo de maior escolaridade sendo que a assiduidade era maior nesse grupo Em relação ao uso regular das medicações não se observou diferenças entre as três formas terapêuticas.

\section{6}

A importância do treinamento prévio no uso do desfibrilador externo automático por fisioterapêutas e enfermeiros.

Carlos Cezar I. S. Ovalle.

Unidade de Terapia Intensiva - HC - UNICAMP Campinas SP BRASIL.

INTRODUÇÃO: A pronta instituição das manobras de ressuscitação cardiopulmonar (RCP) e o uso do desfibrilador externo automático (DEA) por profissionais não médicos tem se mostrado altamente eficaz no atendimento de vítimas de parada cardiorespiratória (PCR) intra-hospitalar. Porém, no Brasil este procedimento ainda não foi analisado, o que justificou e estimulou realização desta pesquisa.

OBJETIVO: Avaliar a importância do treinamento prévio na utilização do DEA por fisioterapeutas e enfermeiros em hospitais gerais

MÉTODO: Fisioterapeutas e enfermeiros realizaram a simulação do atendimento de uma PCR utilizando o DEA. Grupo I: composto por profissionais com treinamento prévio para o uso do DEA e o Grupo II: sem o treinamento. O cenário fo montado utilizando o manequim AmbuR Man e o desfibrilador Medtronic Physio Control LifepakR 500 de treinamento. Os procedimentos foram avaliados de acordo com o protocolo de utilização do DEA da American Heart Association, incluindo o tempo de chegada no leito até a aplicação do primeiro choque, a colocação correta das pás adesivas e o tempo total de atendimento.

RESULTADOS: 0 grupo I apresentou melhor tempo resposta $(P<0,001)$ e melho desempenho $(P<0,001)$ no atendimento cardíaco de emergência quando comparado ao grupo II.

CONCLUSÃO: No ambiente hospitalar, indivíduos previamente treinados apresentam melhores condições de realizar o atendimento cardíaco de emergência incluindo o uso do DEA, que aqueles não treinados.

\section{5}

Educação individual ou em grupo: impacto no conhecimento da doença, auto-cuidado e qualidade de vida de pacientes com insuficiência cardíaca.

Graziella Aliti, Eneida R. Rabelo, Fernanda B. Domingues, Karen Ruschel, Anelise O. Brun, Flávia P. Pereira, Nadine Clausell.

Hospital das Clínicas de Porto Alegre Porto Alegre RS BRASIL Universidade Federal do Rio Grande do Sul Porto Alegre RS BRASIL

A abordagem em equipe multidisciplinar para educação individual ou em grupo sobre a doença, aderência às medicações, restrição de sódio e de líquidos na dieta, atividade física e controle de peso faz parte do manejo da insuficiência cardíaca (IC), embora a estratégia de educação em grupo seja pouco explorada. OBJETIVOS: Avaliar o impacto da educação individual(controle=ctl) ou em grupo (intervenção=interv) no conhecimento da doença, no auto-cuidado e na qualidade de vida (QV)de pctes com IC, antes e após 6 encontros. MÉTODOS: Ensaio clínico randomizado $2: 1$. Foram recrutados 15 pctes para orientação individual e 8 pctes para orientação em grupo, no período de Jan/03 a Fev/05. 0 conhecimento da doença foi avaliado por meio de questionário padronizado com informações sobre a doença e o auto-cuidado, e a QV por meio do questionário de Minnesota. Além disso, foi criada uma variável composta de 4 cuidados essenciais na IC: restrição de sal, de líquidos, controle de peso e prática de atividade física, correspondendo a $100 \%$ o conhecimento destes 4 cuidados. RESULTADOS: A idade dos pctes foi $59 \pm 3$ anos; $70 \%$ de homens, em ambos os grupos; fração de ejeção $34 \%$,e as demais características clínicas semelhantes.

\begin{tabular}{lllllll} 
& CTLPRE & INTERVPRE & $\mathbf{p}$ & CTLPOS & INTERVPOS & $p$ \\
\hline Pctes $\mathrm{n}$ & 15 & 8 & & 11 & 6 & \\
\hline Conh dça & 6,6 & 7,3 & 0,5 & 10 & 12 & 0,1 \\
\hline QV & 34,4 & 42,1 & 0,3 & 26 & 35 & 0,4 \\
\hline
\end{tabular}

Quanto aos 4 cuidados, apenas o grupo interv. no final do seguimento atingiu $100 \%$ deste conhecimento, enquanto no grupo ctl. $54 \%$ obtiveram o percentual máximo de 75. CONCLUSÂO: Foi demonstrado que as 2 estratégias melhoraram o conhecimento da doença e auto-cuidado em relação ao momento basal. Houve uma tendência para redução no escore de QV no grupo ctl. No grupo interv. a variável composta dos 4 cuidados foi mais predominante. Desta forma, ambas as estratégias trazem benefícios no seguimento destes pctes.

\section{7}

Perfil clínico de pacientes admitidos com síndrome coronariana aguda em um hospital de referência em cardiologia.

Emiliane Nogueira de Souza, Rogério Sarmento-Leite, Rúbia Maestri, Camila Bauer Albarrán, Alexandre S. Quadros.

Instituto de Cardiologia do RS I FUC Porto Alegre RS BRASIL.

BASE TEÓRICA: AS síndromes coronarianas agudas (SCA) caracterizam-se por um eventos decorrentes da vulnerabilidade do ateroma, com evolução incerta. Com o objetivo de diminuir a morbimortalidade e aumentar a sobrevida de pacientes, novas terapêuticas foram introduzidas baseadas em evidências de grandes ensaios clínicos.

OBJETIVOS: identificar o perfil clínico e terapêutico dos pacientes com SCA MÉTODOS: Estudo de coorte contemporâneo projetado para observar 400 pacientes admitidos por SCA em um hospital de referência cardiológica. Foram analisadas as características de base dos pacientes, a farmacoterapia utilizada nas 24 horas da admissão hospitalar e a classificação por um escore de risco. Os desfechos foram morte, IAM não-fatal e intervenções como angioplastia e revascularização do miocárdio. Para estimativa de risco (RR) foi realizada análise bivariada.

RESULTADOS: Houve predomínio de pacientes do sexo masculino $(60,5 \%)$, da cor branca $(86,9 \%)$, com média de idade de $62 \pm 11$ anos. Dados preliminares de 238 pacientes mostraram o sexo masculino $(R R=1,91)$, cor branca $(1,83)$, hipertensão arterial sistêmica $(1,22)$, dislipidemia $(1,06)$ e intervenções (ACTP e CRM) prévias $(1,01)$ e tendência de diabetes, idade avançada, tabagismo e história prévia de IAM como preditores dos desfechos combinados em até 30 dias da internação hospitalar. Dentre as medicações, verificou-se o uso de AAS $(93,6 \%)$, betabloqueadores $(83,1 \%)$, inibidores da enzima de conversão da angiotensina $(52,9 \%)$ e estatinas $(39,9 \%)$ nos pacientes. Classificaram-se os pacientes por grupo de risco, de acordo com o escore TIMI: baixo (TIMI 0,1 \&2) $22,7 \%$, médio (TIMI 3 \& 4) 53,8\% e alto (TIMI 5,6 \& 7) 23,5\%, sendo este último com maior associação a eventos.

CONCLUSÃO: Os dados apresentados são concordantes aos achados na literatura ratificando os fatores de risco clássicos para a SCA Já alguns medicamentos comprovadamente benéficos ainda são subtilizados no início da terapêutica. 


\section{8}

\section{Remoção de introdutor arterial pós-intervenções coronárias percutâneas: médico residente versus enfermeiro.}

Alex Sandro Teixeira de Oliveira, George Cesar Ximenes Meireles, Luciano Mauricio de Abreu Filho, Antonio A.C.Forte, Marcos Kiyoshi Sumita, Jorge Hideki Hayashi, José Del Carmen Solano Aliaga.

Hospital Stella Maris Guarulhos SP BRASIL.

OBJETIVO: Comparar os resultados da retirada de introdutor pelo enfermeiro pelo médico residente em Cardiologia Intervencionista em pacientes submetidos a intervenção coronária percutânea.

MÉTODO: Trata-se de registro prospectivo em 100 pacientes com diagnóstico de insuficiência coronária aguda ou crônica, submetidos a intervenções coronárias percutâneas via femoral, no período de setembro a outubro de 2004, divididos em 2 grupos: Grupo A (GA) - enfermeiro ( $n=48$ pacientes) e Grupo B (GB) médico residente $(n=52$ pacientes). Foram excluídos os pacientes com complicações vasculares ou locais durante o procedimento, obesidade mórbida, doenças hemorrágicas e doença vascular arterial periférica. Hematoma pequeno foi definido como inchaço palpável no local da punção medindo 2 a $4 \mathrm{~cm}$ moderado de 4 a $6 \mathrm{~cm}$. Complicação maior foi definida como sangramento com diminuição da hemoglobina $>3 \mathrm{~g} / \mathrm{dl}$ e do hematócrito $>10 \%$ e cirurgia vascular. A dose de heparina foi $100 \mathrm{UI} / \mathrm{Kg}$ EV. Os introdutores foram retirados após controle do tempo de coagulação ativado $(<180 \mathrm{~s})$ e foi realizada compressão manual por período mínimo de 15 min. Após a compressão, os pacientes permaneceram em repouso no leito por 6 horas.

RESULTADOS: A idade dos pacientes foi $59,54 \pm 11,1$ (GA) e $61,7 \pm 10,4$ (GB) anos com predomínio do sexo masculino $(\mathrm{GA}=75 \%$ e $\mathrm{GB}=58 \%$ ). Os introdutores e cateteres foram 7F. O tempo de compressão foi $19,4 \pm 3,1$ min. no GB-A e $19,6 \pm 3,1 \mathrm{~min}$. no $\mathrm{GB}(\mathrm{p}=0,76)$. Ocorreram 8 hematomas no $\mathrm{GA}$ ( 7 pequenos 1 moderado) e 9 hematomas no GB (7 pequenos e 2 moderados), $p=N S$. CONCLUSÃO: A retirada de introdutor arterial, após intervenções coronárias percutâneas, pode ser realizado pelo enfermeiro ou médico residente em Cardiologia Intervencionista com segurança e sem complicações maiores.

\section{9}

Características do atendimento nas intervenções coronárianas de urgência no laboratório de hemodinâmica.

Hungaro, $M$

Universidade Luterana do Brasil Canoas RS BRASIL.

A síndrome coronariana aguda, em especial o infarto aguda do miocárdio vem sen-do uma das causas mais freqüentes de internação em UTIs. As técnicas de reperfusão pro-porcionaram um melhor prognostico a estes pacientes.

OBJETIVO: Caracterizar as intervenções coronarianas de urgência (Angioplastias Coronarianas Translumial Percutâneas Primá-rias, ACTP $1^{a}$ ) do laboratório de hemodinâmica.

MÉTODOS: Estudo descritivo em um hospi-tal geral privado de grande porte no município de Porto Alegre. Foram estudados todos os procedimentos identificados no período de $1^{\circ}$ de janeiro a 31 de dezembro de 2002 , perfazendo um total de 29 atendimentos.

RESULTADOS: Dos 29 atendimentos com caráter de ur-gência, 20 foram classificados como ACTP1 ${ }^{\text {a }}$ - IAM. Destes pacientes, 16 (80\%) foram do gênero masculino e 4 (20\%) gênero feminino. A média de idade foi de 57 anos. 0 tempo médio porta-balão foi de 144 minutos, com uma variação mínima de 70 minutos e máxima de 262 minutos. 0 tempo médio de duração das intervenções foi de 111 minutos. As arté-rias coronárias comprometidas identificadas no estudo foram. CD-10 (50\%); DA-6 (30\%); CX-3(15\%); Outros-1(5\%), Observou-se o implante de endopróteses coronárias ocorreu em 17 (85\%) dos 20 procedimentos identificados. A utilização de antiplaquetário endove-noso (Abciximab) foi 9 $(45 \%)$ dos procedimentos identificados. A média de permanência no hospital pós-procedimento foi de sete dias.

CONCLUSÃO: Observou-se em relação ao gêne-ro o mesmo descrito na literatura. 0 tempo médio porta-balão foi 54 minutos superior que o indicado na literatura. Os resultados irão subsidiar a equipe multiprofissional do laboratório de hemodinâmica, para agilizar e qualificar cada vez mais o atendimento prestado a estes pacientes.

PALAVRAS-CHAVE: Hemodinâmica, enfermeiros, angioplastia primária.

\section{0}

Desfibrilação externa automática realizada por enfermeiros de unidades hospitalares não críticas.

Höfling C, Vancini CR, Pisoni IC, Silva KR, Granitoff N.

Universidade Federal de São Paulo/Hospital São Paulo São Paulo SP BRASIL.

Na parada cardiorrespiratória (PCR), os atuantes primários têm a chance de salvar vidas por meio da desfibrilação precoce. Diretrizes internacionais recomendam aos profissionais de saúde habilidades em suporte básico de vida (SBV) e no uso de um desfibrilador externo automático (DEA) a fim de facilita a desfibrilação precoce intra-hospitalar, principalmente em áreas não críticas. OBJETIVOS: Verificar o desempenho de enfermeiros de unidades hospitalares não críticas, sem treinamento prévio, acerca do uso do DEA em simulações de PCR e descrevendo facilidades e/ou dificuldades.

MÉTODO: Estudo descritivo tendo com 54 enfermeiros de unidades hospitalares não críticas. Os dados foram coletados mediante o registro em roteiro tipo check list do desempenho na realização da desfibrilação rápida durante simulação com cenário de PCR utilizando manequim e DEA. A seguir, foi aplicado um questionário que abordava facilidades e/ou dificuldades apresentadas.

RESULTADOS: Apenas 17\% ignoraram ou recusaram-se a usar o DEA alegando não ter treinamento ou desconhecer seu uso. Os demais (83\%) realizaram desfibrilação na simulação, apresentando como falhas a ausência de comando de interrupção da RCP (98\%), a falta de comando de afastar as pessoas $(87 \%)$ e erro na localização das pás (22\%). Como dificuldades, $47 \%$ apontaram o fato de não conhecer o aparelho, mas 30\% citaram nenhuma dificuldade. Dentre as facilidades $43,6 \%$ citaram o caráter auto-explicativo do aparelho e $32,2 \%$ o fáci manuseio do mesmo.

CONSIDERAÇÕES FINAIS: Este estudo sugere que as falhas e dificuldades apresentadas pelos enfermeiros podem ser facilmente superadas com treinamento em SBV. Assim, torna-se possível promover a atuação efetiva desses enfermeiros como atuantes primários, colaborando com o sucesso da desfibrilação precoce intra-hospitalar.

\section{1}

Hospital dia em cardiologia (HD): implantação e tipos de atendimento.

Erika Novo, Maria do Carmo Bastos, Fernanda Teixeira, Daniela Shimamoto, Thereza Tagami, Jurema Palomo, Mucio Tavares de Oliveira Junior.

Instituto do Coração (InCor), FMUSP São Paulo SPBRASIL.

INTRODUÇÃO: Hospital Dia (HD) é uma forma de atendimento de curta duração de caráter intermediário entre assistência ambulatorial e a hospitalização. Sua finalidade é atender pacientes que necessitem de acompanhamento médico e de enfermagem diário, mas que não necessitam de internação hospitalar.

OBJETIVOS: Descrever a necessidade de implantação de um HD em Cardiologia e os tipos de atendimentos prestados.

MÉTODOS: Trata-se de um estudo de caráter descritivo. Foi elaborado um banco de dados para registro dos atendimentos onde consta: dia de admissão, tempo de atendimento, grupo de origem, tratamento e procedência do paciente. Todos os pacientes atendidos desde a implantação do serviço foram incluídos.

RESULTADOS: A implantação do HD surgiu a partir da necessidade de maior rotatividade dos leitos das unidades de internação e diminuição dos atendimentos não emergenciais de pacientes que procuravam a Emergência do InCor por descompensação de sua doença de base. De agosto de 2004 a janeiro de 2005 foram realizados 689 procedimentos. Os pacientes foram encaminhados do ambulatório, da emergência e das unidades de internação. Os tipos de atendimento mais freqüentes foram antibioticoterapia parenteral, terapia parenteral pós TX de pulmão, insuficiência cardíaca descompensada e cardioversão química ou elétrica de arritmias supraventriculares.

CONCLUSÃO: A demanda para atendimento em regime de HD em unidade terciária de cardiologia foi: ICC descompensada, cardioversão química ou elétrica de flutter ou fibrilação atrial, antibioticoterapia parenteral e tratamento de complicações pós-transplante de pulmão. Com isso, esperamos diminuir o tempo de hospitalização e o custo do tratamento. 


\section{2}

\section{Resultados iniciais da implantação de Programa Sistematizado de Anticoagulação Oral (PSAO).}

Thacila Regina Mozzaquatro, Silvana Angelina Dorio Nishioka, Martino Martinelli Filho, Cinthya Ibrahim Guirao, Júlio César de Oliveira, Ricardo Alkmim Teixeira, Anísio Alexandre Andrade Pedrosa, Janete Caetano da Silva Jenel do Carmo, Sérgio Freitas Siqueira. InCor - HCFMUSP São Paulo SP BRASIL.

INTRODUÇÃO: análise recente das informações de 411 pacientes em uso de anticoagulante oral, registrados no banco de dados de nossa instituição, revelou que 308 estavam fora da faixa terapêutica ideal, apesar de monitoração médica convencional. Esses dados justificaram a criação de um programa sistematizado de anticoagulação oral (PSAO), a partir de maio de 2004.

OBJETIVO: analisar os resultados iniciais da implantação do PSAO.

MÉTODOS: o PSAO é constituído por equipe multiprofissional: médico, enfermeiro, biologista, farmacêutico e auxiliar do serviço de agendamento. Tem por principio: atuar no estabelecimento das faixas terapêuticas, análisar os resultados de exames, educar e orientar os pacientes, agendar retornos e disponibilizar a medicação, visando um controle eficaz e seguro. Para cada paciente é fornecido um cartão informativo contendo: nome, registro hospitalar, diagnóstico da cardiopatia, motivo da anticoagulação, anticoagulante, faixa terapêutica ideal. A cada retorno são registrados: dose atual, faixa de INR, adequação da dose prescrita e data do retorno. Enquanto aguarda o resultado do exame, são colhidas informações que traduzem o grau de entendimento sobre o uso do anticoagulante (questionário) e ele assiste palestra (enfermeiro) para orientação e conscientização quanto necessidade de adesão correta à nova rotina. Nesse período os pacientes com resultados dentro da faixa estabelecida são dispensados pelo biologista. Quando fora da faixa estabelecida são reencaminhados para o médico.

RESULTADOS: dentre 461 pacientes inscritos no PSAO, 392 tiveram pelo menos um retorno no período de maio a dezembro de 2004 e destes, 228 encontravamse dentro da faixa terapêutica ao iniciarem o programa. Ao final do período analisado, 261 encontravam-se dentro da faixa preconizada enquato 131 estavam fora da faixa.

CONCLUSÃO: A introdução de um PSAO pode proporcionar: maior aderência segurança ao paciente além agilizar o atendimento e otimizar a terapêutica.

\section{3}

Avaliação de fatores de risco cardiovascular em usuários de um parque público de São Paulo.

Mildred P. Ferreira da Costa, Silvia Fürbringer e Silva, Simone Pereira Gabriel Murayama, Hélio Penna Guimarães.

Centro Universitário São Camilo São Paulo SP BRASIL

Instituto Dante Pazzanese de Cardiologia São Paulo SP BRASIL

INTRODUÇÃO: As doenças cardiovasculares constituem atualmente no Brasil as principais causas de morte e respondem por alta morbidade. Objetivos: A demonstrar dos fatores de risco cardiovasculares em usuários do Parque Independência, município de São Paulo, no mês de abril de 2004.

MATERIAL E MÉTODOS: A metodologia adotada foi quantitativa, descritiva exploratória a partir da demanda espontânea de um evento de extensão da universidade no parque. Os usuários do Parque foram avaliados quanto às principais variáveis relacionadas à presença de fatores de risco cardiovasculares. RESULTADOS: a população estudada constituiu-se de 127 pessoas, das quais 66 $(51,96 \%)$ eram do sexo feminino e $61(48,03 \%)$ do sexo masculino; a faixa etária variou de 27 a 87 anos, com predominância na faixa entre 47 e 77 anos (62,20\%); 47 pessoas $(37 \%)$ possuiam antecedentes familiares para doenças cardiovasculares; 107 (84,25\%) desconheciam ter ou não hipercolesterolemia; 111 (87,40\%) desconheciam ser portadores ou não de Diabetes mellitus; 41 (32,28\%) referiram ser hipertensos e $86(66,71 \%)$ desconheciam ser portadores desta patologia; 35 ( $27,55 \%)$ eram tabagistas ; 30 (23,62\%) eram ex-tabagistas; 86 pessoas $(67,71 \%)$ referiram praticar atividade física regularmente; 56 (44,09\%) consideraram-se estressados; das mulheres menopausadas 22 (56,41\%) não faziam reposição hormonal; os homens apresentaram índice cintura/quadril maior do que as mulheres, porém foi observado um índice de hipertensão arterial maior nas mulheres.

CONCLUSÃO: A maior parte das pessoas avaliadas praticam atividade física regularmente, não são tabagistas, desconhecem ser portadores de diabetes, hipertensão arterial e hipercolesterolemia, a maioria das mulheres em idade fértil não faz uso de contraceptivo oral; entretanto, o número de mulheres com níveis pressóricos elevados foi maior que o verificado nos homens e a maioria das mulheres menopausadas não faz uso de reposição hormonal. Para uma avaliação mais precisa, seria necessário a avaliação dos indivíduos através de exames laboratoriais, uma vez que o desconhecimento de portar tais patologias não implica na inexistência das mesmas.

\section{4}

\section{Crenças dos enfermeiros sobre a realização do estudo} hemodinâmico.

Pinto, Cristiano J.M., Colombo, Roberta C.R.C., Gallani, Maria C.B.J.

Universidade Estadual de Campinas Campinas SP BRASIL.

FUNDAMENTO: Na prática do enfermeiro é freqüente o relato de dificuldades para realizar o estudo hemodinâmico $(E H)$ por meio do cateter de artéria pulmonar (CAP). A identificação dos fatores que contribuem na formação da intenção do enfermeiro em realizar o $\mathrm{EH}$, pode proporcionar subsídios para o delineamento de intervenções educativas que permitam direcioná-lo à uma intenção favorável ao comportamento.

OBJETIVO: Identificar por meio da Teoria do Comportamento Planejado, as crenças de atitude, normativas e de controle que influenciam a intenção comportamental do enfermeiro em realizar o $\mathrm{EH}$.

DEFINIÇÃo: Trata-se de um estudo exploratório.

MÉTODO: Os dados foram obtidos por meio de entrevista junto a 23 enfermeiros de UTI em três hospitais de Campinas, SP. A natureza exploratória do estudo permitiu a análise qualitativa dos dados.

RESULTADOS: Dentre as Crenças de Atitude, destacam-se as crenças afetivas negativas e positivas, e as vantagens e desvantagens da realização do EH. Nas Crenças Normativas, foram evidenciados os referentes sociais positivos: médico, enfermeiro, paciente; e os fatores estimuladores: responsabilidade e interesse na recuperação do paciente; como referentes negativos o serviço de educação continuada; como fatores que desestimulam: déficit de conhecimento e pequen utilização dos dados do EH pelo médico. Dentre as Crenças de Controle, destacaram-se como facilitadores e/ou dificultadores: equipamentos, conhecimento e sobrecarga de trabalho.

CONCLUSÃO: Este estudo permitiu conhecer uma ampla gama de crenças dos enfermeiros sobre a realização do $\mathrm{EH}$, que subsidiarão a construção de escalas psicométricas para melhor compreensão desse comportamento, o que propiciará o desenho de intervenções educativas mais efetivas.

\section{5}

\section{Perfil dos pacientes cardiopatas quanto ao risco de queda.}

Letícia Orlandin, Emiliane Nogueira de Souza, Jaqueline Sauer, Mônica Conca Jaime. Instituto de Cardiologia do RS IFUC Porto Alegre RS BRASIL.

INTRODUÇÃO: A queda de pacientes é um dos tipos de acidentes que mais ocorrem entre adultos mais velhos, podendo haver graves conseqüências, além do aumento do tempo de internação, custo do tratamento e dúvidas com relação à qualidade do serviço de enfermagem e à responsabilidade profissional. Considerando a queda de pacientes hospitalizados um evento adverso, o serviço de enfermagem das instituições hospitalares deve conhecer o perfil de sua clientela para que as necessidades de assistência possam ser levantadas adequadamente auxiliando na escolha do método de assistência a ser utilizado. OBJETIVO: Caracterizar o perfil dos pacientes cardiopatas quanto ao risco de queda com vistas à implementação de adequada assistência de enfermagem.

MATERIAL E MÉTODOS: Pesquisa descritiva/prospectiva; os dados foram coletados através de um instrumento próprio com questões fechadas, por meio de consulta ao prontuário e uma entrevista com o paciente ou familiar durante a admissão de enfermagem. A amostra foi constituída de 81 pacientes, maiores de 65 anos, internados em unidades de internação clínica-cirúrgica, em um hospital de cardiologia do sul do Brasil, no período de janeiro a março de 2004. A análise dos dados foi realizada através de estatística descritiva.

RESULTADOS E CONCLUSÕES: Do total de 81 pacientes pesquisados, $34,5 \%$ apresentaram risco de queda conforme o sistema de pontuação. Fatores como idade ? 80 anos $(57,1 \%)$, diminuição da acuidade visual $(53,5 \%)$, hipotensão postural $(60,7 \%)$, diminuição do equilíbrio ao andar (42,8\%) e uso de diferentes tipos de medicamentos $(92,8 \%)$ como diuréticos, anti-hipertensivos e benzodiazepínicos, aparecem como fatores predisponentes à queda ao solo. Os resultados obtidos corroboram a necessidade de adoção de medidas de controle de quedas, incluindo ações preventivas, analíticas e assistenciais pós-queda, de acordo com as características dos pacientes, a fim de monitorizar os fatores de risco, as causas, as complicações e as condutas instituídas. 


\section{6}

\section{Alteração na satisfação sexual de pacientes com doença multiarterial coronária sintomática: The Medicine, Angioplasty or Surgery Study (MASS II)- 48 meses de seguimento.}

Myrthes Emy Takiuti, Priscyla Girardi, Teryo Nakano, Celia Regina S R Nogueira, Jurema Paloma, Neuza Lopes, Aecio Flavio Teixeira de Gois, Ludhmila Abrahão Hajiar, Whady Armindo Hueb, Luiz Antonio Machado Cesar, Sergio Almeida de Oliveira, Jose Antonio Franchini Ramires.

Incor - HCFMUSP São Paulo SP BRASIL.

INTRODUÇÃO: A coronariopatia exerce fortes impactos físicos, emocionais e sociais comprometendo de forma importante a qualidade de vida, inclusive o aspecto sexual. O objetivo desse trabalho é analisar o impacto da doença arterial coronária assim como o tipo de tratamento intervencionista (cirurgia ou angioplastia) ou clínico nos pacientes com DAC e função ventricular preservada. MÉTODO: A atividade sexual foi avaliada por meio de um questionário de auto avaliação aplicado por uma enfermeira no pré tratamento, $6,12,24,36$ e 48 meses de seguimento.

RESULTADOS: Não existe diferença significante em relação a satisfação sexual entre os 3 diferentes tipos de tratamento em todos os tempos de seguimento. Foi observado que o grupo do sexo masculino apresenta um maior índice de satisfação no pré tratamento, e em todos os tempos de seguimento, porém não foi observado melhora dessa satisfação em nenhum dos tempos do seguimento. Não foi observado diferença de resultados em relação à satisfação sexual entre os grupos de pacientes diabéticos e não diabéticos.

CONCLUSÃO: O tipo de tratamento não interfere na satisfação sexual do pacientes estudados, porém os homens mostram uma percepção de melhor qualidade sexual que as mulheres.

\section{7}

A teoria do autocuidado no manejo dos fatores de risco em pacientes pós-infarto agudo do miocárdio.

Silvia Goldmeier, Iran Castro.

Instituto de Cardiologia do RS IFUC Porto Alegre RS BRASIL.

OBJETIVO: Avaliar a efetividade na redução de fatores de risco para doença arterial coronariana (DAC) estabelecida,em pacientes internados em uma UTI cardiológica, adicionando um programa de enfermagem ao tratamento convencional, baseado na Teoria do Autocuidado.

METODOLOGIA: Ensaio clínico randomizado, em uma população de 74 pacientes com primeiro infarto. A intervenção (Grupo A) constituiu-se de um programa de ações educativas de enfermagem. O grupo controle (Grupo B) foi tratado convencionalmente, sem a intervenção de enfermagem. Os fatores de risco (FR) analisados e submetidos foram obesidade, hipertensão arterial e tabagismo.

RESULTADOS: A idade variou de 36 a 69 anos, predominando o sexo masculino (78\%). Observou-se que, após a intervenção de enfermagem (Grupo A), os pacientes tiveram uma redução no número dos $F R$, comparados ao Grupo $B(p<0,014)$. 0 número de fumantes no grupo $A$ foi significativamente menor $(p<0,003)$ que no grupo B, observando-se redução de $85 \%$ e $33,33 \%$, respectivamente.

CONCLUSÃO: Prevenção é uma medida de ação de saúde necessária e imprescindível no combate aos FR para DAC. O programa de intervenção de enfermagem implementado foi efetivo, de baixo custo, metodologia simples e boa resolutividade. Somado às intervenções médicas, pode contribuir na redução da mortalidade por DAC

\section{8}

Período pré-transplante cardíaco - visão da enfermagem: relato de caso.

Caroline Rodrigues Doria, Maria Antonieta P. de Moares, Andréia Coutinho.

Instituto de Cardiologia (IC-FUC) Porto Alegre RS Brasil.

O transplante cardíaco é o procedimento terapêutico mais efetivo que se pode oferecer aos cardiopatas em fase terminal, além de melhorar a qualidade de vida. No entanto foi o emprego da ciclosporina em 1980 que propiciou grande desenvolvimento nesta área. Mesmo que a falta de conscientização da população para obtenção de doadores seja um fator limitante, faz-se necessário que haja uma equipe multidisciplinar apta a prestar uma assistência de qualidade.

RELATO DE CASO: Homem, 56 anos, ex-tabagista, hipertenso, com miocardiopatia dilatada reumática, em uso de marcapasso desfibrilador implantado após episódio de fibrilação ventricular. Evoluiu com insuficiência cardíaca grau IV (NYHA), sendo encaminhado à lista de transplante há dois anos. Internou por piora clínica, apresentando dispnéia em repouso, ascite e edema de membros inferiores, necessitando uso de drogas vasoativas por $48 \mathrm{~h}$ até ser submetido ao transplante.

DISCUSSÃO: É importante salientar que o paciente no período pré-transplante passa por processo adaptativo complexo, desde a disfunção gradativa de órgãos e sistemas até o momento da cirurgia, que, além de não ter data marcada, muitas vezes não ocorre. Durante o período de espera são necessários cuidados por parte de diversos profissionais para manter o paciente viável para o transplante. Cabe a enfermagem prestar assistência com controle rigoroso dos sinais vitais, do balanço hídrico, além de atentar para prevenção de infecções e, sobretudo, ter aptidão para agir com destreza em possíveis complicações. Além disso, devem intervir nas necessidades básicas comprometidas, proporcionando ao paciente conforto e segurança. 0 profissional de enfermagem, por ser quem desempenha função contínua à beira do leito, precisa estar preparado para esclarecer dúvidas e minimizar ansiedades do paciente e seus familiares. A busca por uma assistência humanizada e bem direcionada por parte de toda a equipe é fundamental, pois reflete numa maior adesão ao tratamento proposto e na valorização pela qualidade da atenção recebida.

\section{9}

Alteração na satisfação sexual de pacientes com doença arterial coronariana submetida à cirurgia de revascularização miocárdica com e sem circulação extracorpórea: MASS III.

Priscyla Girardi, Myrthes Emy Takiuti, Teryo Nakano, Celia Regina S R Nogueira, Jurema Palomo, Aecio Flavio Teixeira de Gois, Ludhmila Abrahão Hajiar, Whady Armindo Hueb, Neuza Lopes, Luiz Antonio Machado Cesar, Sergio Almeida de Oliveira, Jose Antonio Franchini Ramires. InCor - FMUSP São Paulo SP BRASIL.

INTRODUÇÃO: A coronariopatia exerce fortes impactos físicos, emocionais e sociais, comprometendo a qualidade de vida, inclusive o aspecto sexual.

Objetivo: Objetivamos analisar o impacto da doença arterial coronária(DAC) e o tipo de tratamento cirúrgico nos pacientes com DAC pertencente ao estudo MASS III, estudo randomizado, prospectivo com objetivo de comparar a cirurgia de revascularização miocárdica(RM) com e sem circulação extracorpórea (CEC). MÉTODOS: Dos 132 pacientes participantes, 65 foram submetidos a RM com CEC e 67 foram submetidos a RM sem CEC e avaliados prospectivamente durante 1 ano. A atividade sexual foi avaliada por meio de um questionário de auto-avaliação (SF-36 e QCPD) quanto a percepção da qualidade da atividade sexual e os motivos responsáveis pelo comprometimento da mesma, aplicada no pré, 6 e 12 meses após o tratamento cirúrgico.

RESULTADOS: Na condição basal, o grupo sem CEC apresentou percentual maior de insatisfação quando comparados ao grupo com CEC $(p=0.006)$. Entretanto após 1 ano de tratamento, os grupos não apresentaram diferença significativa, indicando uma melhor satisfação sexual no grupo sem CEC. Porém, quando a análise foi estratificada pelo sexo do paciente, o sexo masculino apresentava melhor satisfação sexual tanto no pré-cirúrgico como 12 meses após a avaliação quando comparado ao sexo feminino. $(p<0.001)$. Quanto aos motivos da insatisfação sexual, os homens, queixavam-se de ansiedade, medo, falta de motivação e dor precordial, mais que as mulheres $(p<0.05)$. Já as mulheres reclamavam mais de insegurança do parceiro $(p=0.002)$.

CONCLUSÃO: Os pacientes submetidos a RM sem CEC apresentaram melhora em relação a satisfação sexual quando comparados aos pacientes submetidos a RM com CEC. Além disso, os homens apresentaram uma melhor satisfação na qualidade sexual quando comparados com as mulheres. 


\section{0}

\section{Mediastinite pós-esternotomia longitudinal em cirurgia cardíaca curativos com Alginato de Cálcio e Ácidos Graxos essenciais - um relato de experiência.}

\section{Letícia Orlandin, Janete Feula.}

Instituto de Cardiologia do RS I FUC Porto Alegre RS BRASIL.

INTRODUÇÃO: A mediastinite é uma grave complicação infecciosa do pós-operatório de cirurgias cardíacas. Muitos pacientes, após a mediastinotomia exploradora retornam à unidade de intensivismo com a ferida operatória aberta, sendo necessário à utilização de curativos eficientes que auxiliem no processo cicatricial e no combate à infecção... Os curativos de alginato de cálcio são compostos por fibras de não-tecido, derivados de algas marinhas, com íons de cálcio e sódio incorporados as suas fibras. Esse curativo é indicado para feridas abertas, cavitárias ou não, altamente exsudativas, que necessitam de estímulo rápido de granulação.

OBJETIVO: Relatar a evolução das feridas operatórias com curativos com alginato de cálcio e ácidos graxos essenciais

METODOLOGIA: Estudo prospectivo/descritivo que envolveu uma população com diagnóstico de mediastinite, com amostra de três indivíduos. A evolução do processo cicatricial foi acompanhada pela enfermeira da unidade e pelo cirurgião. O período observacional foi de janeiro a junho de 2004.

RESULTADOS: Os três indivíduos da amostra realizaram cirurgia de revascularização do miocárdio. Com o uso desse tipo de cobertura, a alta hospitalar se deu em torno de 25 dias após o início de sua utilização. Todos os indivíduos apresentaram melhora significativa na evolução das feridas operatórias; com 15 dias de uso as feridas operatórias já apresentavam condições de nova ressutura, pois apresentavam-se limpas com tecido de granulação.

CONCLUSÃO: É importante ressaltar que os curativos com alginato de cálcio e AGE mostraram-se efetivos no tratamento das feridas operatórias auxiliando no processo de desbridamento autolítico, promovendo a quimiotaxia e angiogênese do leito da ferida. Cabe ao enfermeiro e ao médico avaliar a ferida e identifica os objetivos a serem alcançados naquele momento da terapêutica, além disso, ambos devem compreender o que esperar do curativo utilizado reconhecendo que nenhum curativo proporciona o ambiente ótimo para a cicatrização de todas as feridas.

\section{2 \\ Escolha da prótese valvar : conseqüências financeiras e sociais ao longo do tempo.}

Paulo de Lara Lavítola, Guilherme Sobreira Spina, Roney Orismar Sampaio, Marcelo Katz, flávio tarasoutchi, max grinberg.

Instituto do Coração (InCor), HC-FMUSP São Paulo SP BRASIL.

INTRODUÇÃO: Há controvérsias na escolha do substituto valvar mais adequado. As próteses mecânicas teriam maior durabilidade, enquanto que as biológicas dispensam anticoagulação oral (ACO). Avaliamos a qualidade de vida e impacto econômico da escolha nos portadores de prótese mecânica , em relação à prótese biológica.

CASUÃ-STICA E MÉTODO: Duzentos e vinte e um pacientes foram acompanhados por 24+/-9 meses após o implante de prótese valvar. Todos os pacientes estavam em ritmo sinusal, sendo 102 ( $46,1 \%$ ) portadores de prótese biológica (GPB) $48 \%$ na posição mitral e $52 \%$ na posição aórtica - e 119 ( 53,9\%) portadores de prótese metálica ( GPM ) â•" $28 \%$ na posição mitral e $72 \%$ em posição aórtica. Os pacientes no GPB não receberam ACO em nenhum momentro após a alta hospitalar. Os pacientes do GPM recebiam ACO para um INR objetivo de 2,5 a 3,5.

RESULTADOS: â•" A CF foi semelhante entre os grupos ( $p=0,1$ ). No GPB, o intervalo médio entre consultas foi de 180 dias para os em CF II $(74,5)$ e 120 dias para os CFIII ( $25,5 \%$ ). No GPM o intervalo médio entre consultas foi de $30 \hat{A} \pm 12$ dias, independente da classe funcional. Ao final dos 24 meses, a classe funcional permaneceu estável. $82,5 \%$ utilizavam transporte coletivo, com média de 4 passagens por retorno. $61,9 \%$ vinham com acompanhante $\tilde{A}$ consulta, levando a um gasto médio com transporte de $\mathrm{R} \$ 8,41$ a cada consulta. Dos pacientes do GPM, $62 \%$ falraram ao trabalho por meio período, e $48 \%$ tiveram gastos com alimentação fugaz, com custo médio de $r \$ 4,00$. 0 grupo GPB teve menor ausência ao trabalho e não tinham gastos com alimentação. $O$ gasto médio anual do GPB foi de $R \$ 18,92$, enquanto que o do GPM foi de $R \$ 124,92$ $(\mathrm{p}<0,01$ ). Dois pacientes do GPM perderam o emprego por faltas ao trabalho, e dois foram internados no período por INR $>18$, com sangramento.

CONCLUSÃO: A escolha da prótese mecânica, em realção Ã biológica resultou em condições hemodinâmicas semelhantes, mas com gasto maior e conseqüências sociais graves.

\section{1}

Quantidade do sono dos pacientes com doença multiarterial coronariana sintomática: MASS II: $\mathbf{4 8}$ meses de seguimento.

Priscyla Girardi, Myrthes Takiuti, Teryo Nakano, Celia Nogueira, Jurema Palomo, Whady Hueb. InCor - HCFMUSP São Paulo SP BRASIL.

OBJETIVO: Avaliar a qualidade do sono nos pacientes com doença multiarterial coronariana submetidos a tratamento clínico, cirúrgico ou angioplastia, um estudo randomizado com o objetivo de comparar as 3 diferentes opções terapêuticas para pacientes com DAC e função ventricular preservada.

MÉTODO: Foram randomizados 611 pacientes, avaliou-se a qualidade do sono por meio do questionário QCPD que inferiu a necessidade do uso de medicação para dormir, a percepção da qualidade do sono e a interferência do problema cardíaco no sono.

RESULTADOS: Em relação aos 3 diferentes tipos de tratamento, não há diferença de resultados nos 3 aspectos avaliados (necessidade de medicação para dormir/ percepção da qualidade do sono e interferência do problema cardíaco no sono). Quando a análise foi estratificada por sexo, observamos que em relação ao uso de medicamento para dormir, $8,2 \%$ dos homens faziam uso no pré e em 48 meses, $7,4 \%$ deles continuaram com o uso da medicação. Das mulheres $16,1 \%$ faziam uso de medicamento no pré e mantiveram um índice de $20,5 \%$ em 48 meses. Dos homens $85,7 \%$ referem uma boa satisfação do sono e $73,9 \%$ das mulheres referem o mesmo no pré. Essa diferença se manteve em 48 meses. A idade não interferiu no uso de medicamento para dormir. Tanto no grupo ? 65a e $<65$ $(83,2 \%$ e $81.6 \%$ respectivcamente) referem ter uma boa qualidade de sono.

Aos 12 meses no grupo de pacientes ? 65a é observada uma diminuição $(84,25 \%)$ da satisfação do sono em relação ao grupo de pacientes < 65a $(90,2 \%)$ p 0,045. CONCLUSÃO: Concluímos que as mulheres tem uma pior qualidade do sono e uma maior necessidade de medicamentos que os homens, em relação a idade não houve diferença estatística significativa aos 48 meses nos pacientes do MASS II.
643

Implantação $1^{\circ}$ curso de pós-graduação lato-sensu de enfermagem em cardiologia do Rio Grande do Sul: da necessidade à realidade.

Maria Antonieta P. Moraes, Eneida R Rabelo, Lucia C Pellanda, Karina de Oliveira Azzolin, Jaime A Schimitz, Marta R Boaz, Sílvia Goldmeier.

Fundação Universitária de Cardiologia-IC/FUC Porto Alegre RS BRASIL.

A doença cardiovascular é um importante problema de saúde pública, sendo a principal causa de morbi-mortalidade no mundo ocidental, o que se traduz em custos com assistência médica de grande impacto econômico. Nesta cenário, o Ministério da Saúde publicou em 06/2004 a portaria no 1169 que institui a Política Nacional de Atenção Cardiovascular de Alta Complexidade. Dentre as exigências para o credenciamento de instituições que visam garantir aos pacientes a assistência nos vários níveis de complexidade, por intermédio de equipes multiprofissionais qualificadas, está a necessidade de enfermeiros especialistas em cardiologia.

OBJETIVOS: Descrever a experiência da criação do $1^{\circ}$ curso de Especialização de Enfermagem em Cardiologia do Pós-Graduação do IC-FUC do RS.

MÉTODOS: Estudo descritivo para relato de experiência. Resultados: Em 08/2005 teve início a primeira turma com 25 alunos. Entendemos que para a preparação dos alunos as seguintes disciplinas contemplariam um conhecimento especializado, científico e atualizado sobre os diversos temas na área cardiovascular: anatomia, fisiologia e semiologia ; fisiopatologia das cardiopatias, emergências cardiológicas, bioética, seminário em cardiologia, metodologia da pesquisa, administração e gerenciamento. Com a finalidade de transposição da teoria à prática os alunos terão 60 horas de estágio no IC-FUC. As monografias de conclusão de curso contemplam projetos de pesquisa na área de enfermagem em cardiologia, as quais serão entregues em formato de artigo, o que certamente contribui para o crescimento acadêmico, crítico e reflexivo dos alunos no cenário científico.

CONCLUSÃO: 0 investimento em formação e titulação de recursos humanos é atualmente uma meta a ser alcançada pelos profissionais envolvidos no cuidado à saúde. Desta forma, nossa preocupação com a criação do $1^{\circ}$ Curso de PósGraduação em Enfermagem do RS é especializar enfermeiros na área de cardiologia utilizando um referencial científico, acadêmico, técnico-gerencial e humanístico para embasar e consolidar o desenvolvimento de competências e habilidades necessárias para o cuidado de pacientes cardiopatas. 